\title{
Upgrading community treatment through a mental health court
} Heathcote Wales

\author{
Address: Georgetown University Law Center, 600 New Jersey Ave. N.W., Washington, D.C. 20001, USA \\ from WPA Thematic Conference. Coercive Treatment in Psychiatry: A Comprehensive Review \\ Dresden, Germany. 6-8 June 2007 \\ Published: 19 December 2007 \\ BMC Psychiatry 2007, 7(Suppl I):S35 doi:10.1 186/I47I-244X-7-SI-S35
}

This abstract is available from: http://www.biomedcentral.com//47I-244X/7/SI/S35

(C) 2007 Wales; licensee BioMed Central Ltd.

\section{Background}

To determine whether a mental health court can reduce recidivism and improve treatment retention.

\section{Methods}

The sample is 65 persons, co-morbid with substance abuse and severe mental illness, who volunteered for mental health court after conviction of a felony or serious misdemeanor over a four-year period. Their jail days, hospital days, and arrests and convictions post-MHC are compared to their history over a comparable period prior to entry. Outcomes of graduates are compared to those discharged to other treatment programs and those who fail out of the program. Qualitative information is collected from observation of court sessions and interviews.

\section{Results}

Gender (female) and age (>30) correlate with success in the program and reduced recidivism, but nature of index crime (felony or misdemeanor; property or person or drugs or public order), diagnosis, and type of substance abused do not. The two-thirds who don't fail (return to prison) remain connected with treatment following graduation or discharge.

\section{Conclusion}

Mental health courts can reduce recidivism and improve treatment retention. Successes appear to be attributable primarily to high levels of court supervision over: (1) participants; and (2) the disparate provider agencies (probation, ACT team, housing, employment, etc.) serving participants. Improved provider coordination has spill over effects for other persons with mental illness, and has induced improved funding from the state legislature. 